\title{
What is lost and what remains: an exploration of the pedagogical challenges of online discussions in two online teacher education learning communities
}

\author{
KAREN ARMSTRONG and MARGARET MANSON \\ York University
}

\section{Introduction}

Online discussion has emerged as an increasingly common forum for conversation and professional reflection in teacher education. Across Canada, Australia, the United States and the United Kingdom, numerous universities have experimented with various forms of online discussion in teacher education programs. However, few scholars have explored the particular pedagogical challenges of creating meaningful discussions in online teacher education environments. In this paper, we examine some of these challenges and discuss how they might be met in the design of online courses in teacher education. Our intention is to provoke critical reflection on online teaching and contribute to the development of more robust online discussions in teacher education.

\section{Background}

Over the past decade, numerous scholars have argued for the benefits of online learning. For example, Zhao, Englert, Chen, Jones, \& Ferdig (2000) have argued that online discussions help to bring together teachers and students at a variety of levels who would otherwise not have opportunities to interact. Similarly, Hough, Smithey, \& Evertson (2004) have suggested that online discussions can help to mitigate feelings of isolation common to both teaching and learning about teaching. Such discussions offer the promise of mediating perceived obstacles of distance, time and sociality. In addition, Beeghly (2005) and Tiene (2000) have suggested that asynchronous conversations, (online conversations where students participate whenever they desire) provide participants with time to think before responding, whereas synchronous conversations (online conversations that happen in "real time", like "chat") offer possibilities for immediate collaborative group learning and insight. These scholars have also asserted that to some extent, both kinds of online discussions permit participants to voice their thoughts without interruption, a feature that is sometimes missing from face-to-face discussions. In our experiences as online instructors and course designers we have seen many of the benefits that scholars like Zhao, Englert, Chen, Jones, \& Ferdig (2000), Hough, Smithey, \& Evertson (2004), Beeghly (2005) and Tiene (2000) assert. In many ways, online discussions appear to be a promising forum for teachers at all levels, from pre-service through to experienced teachers. However, few scholars have examined the challenges of online discussions, particularly as found in teacher education courses.

In this paper, we consider some of the challenges of online discussions in the context of two courses that we have taught with practicing teachers and pre-service teacher candidates. The first is an example of asynchronous conversation in an exclusively online distance education course. In this course, the participants never meet face-to-face and know each other only through these online conversations. The second course is a 'blended environment' (Graham 2004) that incorporates online discussions and face-to-face meetings. The online discussion component of this course includes 
synchronous chat and the generation of discussion threads which respond to specific topics.

From a curriculum perspective, we are interested in the ways in which instructional technology continues to reinvent itself. Through our experiences as online course designers and educators we have watched the ways that instructional technology has evolved, moving through transformations that demand "a bridge among ideas, disciplines, people, texts, processes...contexts, educational purposes and outcomes, theory and praxis" (Semali \& Pailliotet, 1999, p. 4). Central to our focus on literacy issues in relation to such transformations is an understanding that, as Alvermann \& Hagood (2000) point out, students need "to develop critical understanding of how all texts (both print and non print) position them as readers and viewers within different social, cultural, and historical contexts" (p.193). In this way, two questions became important for our inquiry: first, what were the demands of the technological contexts in which students' work and exchanges took place? and second, what was the nature of the peer learning that emerged from within the online contexts we had created? For our purposes, we regard peer learning as a process that facilitates students' literacy skills and develops critical thinking, communication skills, and content knowledge through community building, meaning making, and reflective practices. While much investigation of peer-learning relationships is directed toward face-to-face interactions, we hold that the increasingly prevalent application of technology in learning environments requires that more attention be focused on examining peer learning in the context of online teaching and learning. Mason (1998) suggests that the nature of learner participation in structured online discussion, collaborative online activities, online assessment, and interactive course material, offers new (?) ways of promoting constructivism in online pedagogy. She observes that technology may enable egalitarian participation, but also argues that a good online discussion is dependent on the ways in which individuals participate and discussion tasks are structured.

The design of the asynchronous exclusively online teacher education course described below drew on a 'best practices' model that was originally developed in relation to face-to-face classroom practices that illustrated the process of integrating literacies within classroom practices in order to increase learning and improve teaching. Our discussion is organized around some concepts that frame this model to consider what happens when this conceptual framework, and the knowledge formation practices that define it, migrates to an online, virtual environment. In turn, the design of the "blended" online teacher education seminar course, the second course described below, engages with the tensions inherent in attempting to reconstruct face-to-face classroom interactions in a virtual environment. In the context of curriculum development for online teaching and learning, we examine issues that emerged from our self-reflexive inquiry into the pedagogical challenges outlined above. We encountered these tensions in both of the online courses we teach. In the next section, we discuss these courses in more detail. We then outline some of the challenges presented by online discussions and describe some of the ways that we have addressed these challenges.

\section{Description of our courses and their online discussion components \\ Current trends and issues in literacy education: An exclusively Online Course}

The first author teaches two sections of an exclusively online education course to 
teachers several time zones away. Most of these course participants reside in various geographical locations in Western Canada. However, some of the students take the course while teaching in other countries such as Sweden, India, Cambodia, and South Africa. For the most part, the course participants have never met each other and they take this course, Current trends and issues in literacy education, to satisfy the requirements of their literacy education diploma or their diploma in teacher librarianship. The only prerequisites for this the course are the completion of a basic reading methods course and having some basic computer skills. The course enrollment ranges from 22-27 students, with a maximum of 30 students. There are four major assignments, all submitted electronically. No textbook is required for the course; instead online or pdf course articles and films, videos and relevant YouTube clips constitute the course content. The course has been taught in this format since its inception in the year 2000. In the first year that the course was offered, the online discussion component of the course was voluntary. This component was designed as an open forum where students could voluntarily contribute observations and questions as they wished. However, in that year, few students participated in this online discussion area and thus, the following year the forum discussion became an ungraded but mandatory course requirement. Students are now required to post introductions, share their existing conceptions of the term "multiliteracies" and what it embodies, share their initial thoughts about their final assignments and discuss one online feature (webcast, video or article) which had the most significant effect on their own pedagogy and thoughts about education. In this way, the discussion postings are a blend of course content-related sharing, brainstorming about possible ways to proceed with the major assignment and finally, a synthesis of what was learned or what seemed most significant in the course. One of these mandatory discussion postings is due each month of the three-month course. There are no small synchronous group online discussions in this course.

\section{Inquiries into Learning and Inquiries into Schooling: Blended course environment}

The second author teaches a year-long online practicum seminar in a pre-service teacher education program. As part of this multi-section course, students in this program complete a 50-hour field-based placement with an urban community organization during their first year of studies. This placement is coordinated through the faculty's community field experience practicum program. While on placement students participate in an online seminar that addresses questions of community and culture. Both the field-based placement and practicum seminar are linked to two required courses in first-year studies, Inquiries into Learning (first semester) and Inquiries into Schooling (second semester). Participation in the online practicum seminar is designed to encourage a reflective process that enables students to link their course materials to their personal experiences in their placement sites. This aspect of the course is designed to emphasize the faculty's focus on " "participating' in community work rather than 'studying' its various interactions" (Dippo, D, Duran M., Gilbert J. \& A. Pitt, 2008, p. 346). Thus in the context of their online practicum seminar, students are encouraged to explore various dialogical aspects of the relations that they discern between community-based and school-based teaching and learning practices and perspectives (Britzman, D., Dippo, D., Searle, D. \& A. Pitt, 1997).

Over the course of their year-long studies in the online seminar, the students, 
(usually numbering about 10-20 depending on registration), and the instructor meet four times in each semester to pose questions, discuss and reflect upon them, and theorize about their field-based practicum placement experiences. The first seminar meeting in each semester is conducted in person, and the subsequent three meetings are conducted online (for an overall total of eight meetings over the year). In the initial face-to-face meeting, students are introduced to the context and pedagogical purposes of the online seminar and to their field-based practicum. During the subsequent six online seminar meetings, students participate in large group exchanges in the form of discussion threads on Moodle, and a Chat Forum. The former provides time for constructing considered responses and the latter simulates the spontaneous nature of everyday classroom discussion. Provision is also made for individual inquiries and responses in the form of confidential online reflective journals that are submitted directly to the instructor on Moodle. Thus, unlike the first course described above, this seminar course format enables participants to meet with each other in person as well as online in order to establish personal collaborative relationships during their online exchanges.

Online exchanges in this seminar often range from concerns about how to adapt to field-based community contexts in which students feel 'strange', how best to negotiate cultural traditions and intercultural forms of communication, and how to think through the implications that arise in relation to students' own practices of teaching and learning. Key to the students' learning process is the ability to pose generative questions on Moodle in order to seek out a range of responses and interpretations. These responses in turn, help students expand upon and refine their new understandings as they encounter the limits of their own knowledge and experiences. The students' inquiries in this regard are organized through four assignments, the first of which is an online reflective journal, which remains confidential between the student and the instructor. In this assignment, students are asked to post observations and emerging questions on a weekly basis in order to trace and reflect on their experiences and the implications they see for teaching and learning. The second assignment, an online "Question Archive" is structured as an extended inquiry that requires each participant to create a minimum of three postings: one question and two responses to other students in the seminar. Following Dippo et al., (2008) this aspect of the course is designed to help students begin to engage thoughtfully with "the intellectual dilemmas of teaching and learning" in order to consider "how to negotiate the discourses and practices of professionalism that will envelop them before they even begin to teach" (p. 339). The third assignment requires students to develop a field-based inquiry that researches the organizational profiles and activities of the community partners with whom they are placed. This assignment is designed to help students prepare for their culminating one-week school-based placement, which requires them to complete observational inquiries into the school/community exchanges that exist in the schools in which they are placed. By encouraging individual inquiries and selfreflexive meaning-making through online reflective journals, as well as large and smallgroup dialogue in online discussion formats, the online seminar's pedagogical structure aims to provide a productive context in which to investigate the complex nature of teaching and learning in communities. In this way, following Wells (2002), "the 'content' of the curriculum, rather than being an end in itself, is treated as a set of resources that mediate [student] investigations" (p. 203). 
Gulati's (2008) discussion of compulsory online discussions is particularly useful here. In his examination of some of the issues that arise in online course design, Gulati (2008) suggests course designers need to be aware of issues of safety, trust, control and choice. In the following pages we consider all of these issues in the context of the courses we teach.

\section{Challenges of teaching and learning in online environments}

In comparing the online and blended courses described above with traditional face-to-face classes we have taught, we discovered several challenges common to both kinds of teaching. In both online courses and face face-to to-face courses, educators are faced with: a) helping the students feel comfortable and safe with each other so that they are fully able to focus on the content of the discussion; b) providing students with sufficient choice throughout all the course/seminar elements so that they feel a sense of control of their own learning; c) ensuring that all students feel engaged and that their contributions are recognized; and finally, d) ensuring that discussions promote higher level thinking skills so as to maximize student engagement and learning. However, in reflecting on the specific challenges of an online environment we identified the following issues that seem to be particular to this format: e) ensuring that students have adequate skills to engage with the technologies used in online learning environments; f) creating a healthy rapport without any visual or aural cues other than on-screen images and text; (g) ensuring rich interactive discussions in an online environment and (h) creating a sense of community and safety in a virtual classroom . In the following section, we examine each of these areas, drawing on Gulati's (2008) framework of "contextual issues of safety, trust, control and choice" (p. 189) to examine how an online environment differs from a face-to-face class in order to arrive at new understandings about the ways that students participate in online environments, and the implications of the nature of their participation for the design of a curriculum for online courses.

\section{Ensuring that Students have Adequate Technological Skills}

One important challenge in designing online learning environments is that students bring a wide range of experiences with technology to their course work. Some students are very comfortable logging in, finding the right discussion group and posting their questions and responses. However, other students struggle with all of these activities. Both students and instructors can also struggle at times with technological catastrophes and glitches. Sometimes servers go down at the very moment that students are submitting a post or an assignment. Sometimes assignments become garbled or go completely missing in cyberspace.

Familiarity with technology can influence students' feelings of safety in online course discussions. We have observed that in the exclusively online course, students often feel unsafe and need one-on-one coaching as they venture forth to try the technology and begin to work their way through the course website. In order to facilitate an easy transition into using the tools of the course, students are sent preliminary files about a month before the first day of class when they can officially log into the course website. These files detail the dates of the assignments, full disclosure as to what is required for each assignment, sample assignments as well as details of the questions for each discussion posting, and technical information such as how to contact the instructor. 
Thus, by the time the introductory discussion postings start participants are familiar with the entire course layout and its assignments. This is different from a face-to-face course in which the instructor structures the course through time rather than space and is, to many students, a distinct advantage of an online environment.

Within the blended environment, students' feelings of control and safety related to instructional technology are addressed through an introductory workshop offered during their the students' orientation session to the practicum seminar and their community placements. During this workshop students establish and log into their faculty email accounts, and are guided through the initial steps of accessing Moodle, and explore the ways in which they will interact with each other through the structures of the online seminar design.

\section{Creating a Healthy Rapport without Visual or Aural Cues}

In face-to-face classes, visual and aural cues such as eye contact, intonation, and tone are important features of communication. These kinds of cues help instructors "read" their classrooms and provide important opportunities to clarify or simplify when it is necessary. When our students indicate a lack of understanding through puzzled expressions, we can rephrase or repeat what we have said. When our students appear bored we can use gentle humor to bring them back to the task at hand. In face-to-face classes, physical and visual cues and conversational exchanges help instructors to be more immediately responsive to student needs and to tailor discussion to individual needs. In an online environment, such cues from our students and such opportunities are often missing or — in the case of humor — can be misunderstood completely.

To account for the absence of these cues, the instructor of the asynchronous exclusively online course is consistently warm and friendly in her communications with course participants, constantly stressing that they should feel free to ask questions, no matter how inconsequential. She uses such niceties such as thanking students for their assignments, discussion contributions, and questions. These are strategies designed to foster a sense of safety and trust for her students.

In the blended environment, the instructor has had some opportunities to establish a healthy rapport with her students before they begin to interact online. However, for the online component of the course, she posts discussion outlines for each online session that include two to three questions to initiate exchanges, participates actively in the discussion, and references useful connections to course materials and community placements so that her students continue to feel supported in their learning. In the exclusively online course, the instructor emailed students the course description, outline, assignment descriptions and deadlines as well as tutorials so that these students entered the course with much knowledge of what was to come. As well, all questions from incoming students are answered within a few hours if not earlier and more questions were sought so that they felt strong support and commitment to their comfort in this new learning environment.

In considering the lack of visual and aural cues in the online classroom, it is important to note that issues of safety and trust can also emerge for instructors in these environments. In the case of the exclusively online course the instructor generally has a limited knowledge of the age, levels of engagement, or teaching experience of the participants in her course. While students are usually asked to introduce themselves at the 
beginning of any on-line course, a student who describes herself, for example, as a teacher 'on call' may have twenty years of teaching experience and may hold more than one degree, or she may be a newly-graduated teacher with little experience or further training. In a face-to-face environment, an instructor can have some sense of how old her students are through a glance, and can, to some degree, estimate the general level of experience in her class. In an online environment, much information is missing, and assumptions can be made by students and instructors. In this context, the instructor does not really "know" the students until they start submitting postings and assignments

In addition, every conversation, indeed every word exchanged between student and instructor is documented in online courses. This permanent archive of conversation can cause both instructors and students anxiety concerning the tone, grammar and possible misreadings of their postings or emails. While Gulati (2008) argues that students often feel powerless in light of their instructor's surveillance, it is important to note that feelings of anxiety, powerlessness and vulnerability can affect instructors as well as students in the unusual faceless environments that characterize online courses. as instructors may also be under constant scrutiny.

\section{Insuring Rich Interactive Discussions}

In both the exclusively online course and the blended course, the online discussions rely on student participation for success. In the exclusively online course, if there is no discussion at all, the course will resemble former paper-based correspondence courses in which students learn in complete isolation, submitting written assignments and receiving feedback from the instructor alone. Ensuring rich interactive discussions is one of the key tasks that any online course designer must consider.

The Question Archive assignment, developed for the blended learning seminar attempts to address this problem by creating a framework that structures, and thus models, interactive exchange. This assignment requires three actions: posing a question, responding to another students' question, and replying to a response posted about your own question. These three actions are the minimum required postings from every student during the online discussion component of the course. While some students are satisfied with completing these basic requirements, several others usually continue to use the framework and often pursue lengthy discussions that exceed the expectations of the instructor. Through the Question Archive, students begin to take up responsibility for generating meaningful discussion.

However, in order to encourage rich interactive discussions, it is important that students also feel that they have the choice to remain silent. Brookfield (1986) warns that enforced or coerced participation can result in learners either being increasingly physically or mentally absent, which can lead to "disengaged learners who may fail to acknowledge new ideas, skills and knowledge" (p. 121) and Kelly (1970) argues that "course designs that view observable participatory roles in discussion as learning, and silent roles as not learning" use teachers' power positions "to enforce conformity" in learning processes (p. 8). For Beaudoin (2002), a learning construct that justifies compulsory contribution wrongly assumes that the process of articulating ideas to a formal authority is a critical element of student learning. Brookfield (1986) adds that "the surveillance and disciplinary power of the teacher, who has normalized judgment for 
compulsory participation, may lead the silent learner to feel pressured and powerless to continue silent learning. The fear of losing marks will further deter learner confidence". In addressing the issue of choosing to be silent, Gulati (2008) points out that, "online discussion spaces are accessible anytime and anyplace, nevertheless it is naïve to suppose that decisions to participate, share and challenge ideas are neutral" (p.188).

In designing an online discussion it is important to consider the extent that the choice to remain silent is available to students and the implications that students' silence can have on online teaching and learning. One of the ways that we have addressed students' need for choice in our courses is that once the basic criteria of responding to required discussion questions has been satisfied, students have a choice as to whether they continue to share further or not.

In examining issues of student silence in online courses, Dennan (2008) found that the majority of her students "learned through the online discussion experience, and that they believed both posting and reading messages contributed to their ability to learn" (p. 1624). In our particular courses, we have found that this type of learning is evident in the students' written assignments as they often referred to salient points of the class discussions, even though at the time of the discussion they did not appear to contribute fully to its progression. Thus even when students exercised their choice to remain silent after satisfying the required number of postings, it became clear that they had continued to read and reflect on the postings made by their peers.

At the same time, it appeared that the social construction of participants' learning in the exclusively online course was mediated at times by their own memories of prior beliefs and constructs. As they proceeded with their online coursework, their interactions with course materials prompted comparative reflections on their prior understandings about various issues related to literacy, and the ways in which their perceptions had been altered, modified or reinforced by the course readings. One student reflected that as she read over her initial "taking stock" assignment, she was surprised by how much of what she already believed was reflected in and reinforced by the collaborative processes of reading, viewing, and responding to texts and the postings from other participants that were offered throughout the course. At the same time, her knowledge of technology and the range of programs and options available to her, were expanded through her encounters with such course materials and exchanges with others. In reflecting on one course task that focused each week on a single text and response, another student noted that, "it's almost Zen-like to just focus on my own thinking" (Kedves, 2010). For another student, one important insight that emerged from her study of critical literacy frameworks was the discovery of new ways in which she could bring a more critical set of perspectives to her use of the provincial rubrics she used drew on to assess her students' work. The locus of these conversations between selves,: - the "self beginning the course" with the "self evolving through course interactions," was presented by students as a personal internal conversation with the authors of the various articles and podcasts that comprised some of the course texts, as well as the exchanges with other course participants.

\section{Creating a Sense of Community and Safety in an Online Environment}

Gulati (2008) asserts that developing a sense of community through which "learners can share knowledge and challenge ideas to build understanding" is often 
difficult for face-to-face and online instructors. Gulati (2008) points out that, "in online communication, sole reliance on text coupled with external controls and tutor surveillance may make it even more difficult for learners to feel a sense of belonging to a social learning network" (p. 188). As instructors we feel it is our ethical responsibility to help students feel comfortable and safe with each other. Within the blended environment, addressing students' feelings of safety in online discussions are approached from two perspectives, a) familiarizing participants with the Moodle platform in a workshop offered during their orientation session (as described above) and b) directly addressing and discussing ethical issues in terms of how we listen to and respond to others. Through readings, and discussion, students are introduced to ethical ways of listening and responding and are asked to consider their own roles in creating a welcoming learning environment. Indeed ethical questions are often provoked by students' initial discussions of their online postings. Students often experience a sense of vulnerability when their classmates respond to their statements and questions. While this experience is not always easy, many students note that the process of posting and responding to others provides them with more complex insights into their own learning. For example, one student noted that the responses he received to his posts about his placement in a rehabilitation centre for youth and children with special needs. moved him to question the nature of inclusive education, and the need to define what might be meant by the terms 'inclusive', 'segregated', and 'integrated', particularly in relation to the education of special needs students.

His process of engaging with the contradictions he had encountered, emerged in part through his online discussions with peers, whose reciprocal questioning and comparative observations drawn from their own personal and professional experiences expanded the scope of his considerations. Key to this transformative process was his willingness to reveal to other participants in the online seminar his own uncertainty about coming to know, and the other participants' non-judgmental and collaborative approach to exchanging and producing knowledge about teaching and learning.

In both the asynchronous exclusively online course, and the blended course we also worked to establish a sense of community and safety by tolerating a certain amount of "off task talk". Barkaoui, So, \& Suzuki (2005) observe that if we look at "off task talk" from an Activity Theory perspective, such talk can be seen to "represent an action, albeit a socio-affective one, within a larger cognitive activity" (15). In the context of online teaching and learning, we both tolerate and to some extent encourage "off task talk", as a means of facilitating and contributing to collaborative learning. Such talk is part of the everyday contexts in which we learn and work and as such is an essential component for establishing a sense of community, and provoking the processes of knowledge building and sharing that mark collaborative learning. Off task talk is an important element in community building and fostering feelings of safety and trust within online groups, particularly in courses that are conducted exclusively online in which participants cannot see each other and are, for the most part, complete strangers.

In both the blended learning and the exclusively online environments, students begin to develop a great deal of trust amongst each other, evidenced by their sharing of person information - about weddings and holidays for example - and the posting of off task talk in the content discussion groups. In the blended learning seminar, participants who interact in other face-to-face settings often open their online sessions with the kinds 
of greetings and comments that suggest they are already engaged in conversations and have shared understandings that they are taking up again in the seminar forum. In general, neither instructor responded to these additions, either to discourage them or respond to them, as we feel these comments enhance the feelings of collegiality and trust amongst online participants in both environments. Indeed some quite candid discussions take place in the exclusively online course amongst the very few students who know each other personally and who come to regard the discussion group as a form of personal chat.

\section{Conclusion}

The issue of safety is not only central to participation in discussions, but according to Maslow it is central to all learning (Gulati, 2008).

We return here to the challenges that emerged for us through teaching and learning in online environments. We have used the concepts of safety, trust, choice and control to consider our own learning about and from the nature of student participation in the exclusively online and blended environments in which we teach. The first challenge designers need to address is students' lack of familiarity with the structures and practices of instructional technology, and the modes of learning and communicating specific to a virtual environment. The second challenge course designers need to contend with is how to provide opportunities for participants to establish a social presence and sustain collaborative approaches to learning that help to mediate the lack of aural, physical and visual cues that mark face-to-face classroom interactions. The third challenge fellow course designers need to address is how to create the grounds for rich interactive discussions in a virtual environment, and the need to allow students the choice of remaining silent. In the contexts of both the exclusively online course, and the blended seminar course, we considered ways in which creating a sense of community could be structured through thoughtful generative questions and exchanges, a range of assignments and exchanges, all designed to foster individual and communal learning and establish a satisfying level of online social presence. A fourth challenge online course designers face is how to encourage a sense of community and trust in an online environment.

An unexpected and remarkable result of our inquiry was realizing that issues of safety, trust, control and choice affect not only the student but the instructor as well. Issues of trust in online environments is dependent upon a sense of being in the presence of a full person and thus, in both the exclusively online course and the blended online seminar course, occasional off-task talk can serve as a way of fostering warmth, trust and a sense of the individual producing the intellectual and personal comments, questions and arguments that appear onscreen. Communication is clearly a complex activity, aspects of which at times become obscured in the flow of online communication. The discussion above suggests that the contextual issues of safety, trust, control and choice, which are central to constructivist learning, are ongoing challenges to our everyday online pedagogies. Returning to our initial question, what appears to be lost in online communities are the contextual nature and distractions of face-to-face communication. What remains is a more streamlined focus on engaging with the significance to students of the pedagogical issues they encounter, and the promise of a deepening of insight and understanding. 


\section{References}

Alvermann, V.E. \& Hagood, M.C. (2000). Critical Media Literacy: Research, theory and practice in "new times". Journal of Educational Research, 93(3) 193-205.

Barkaoui, K., So, M., \& Suzuki, W. (2005). Is it relevant? The role of off-task talk in collaborative learning. Paper currently under review for publication and originally presented at Second Language Research Forum (SLRF), Teachers College, Columbia University, New York City, New York.

Beeghly, D.G. ( 2005). It's about time: using electronic discussion groups with adult learners. Journal of Adolescent and adult literacy, 49(1), 12-21.

Beaudoin, M. (2002). Learning or lurking? Tracking the 'invisible' online student. The Internet and Higher Education, 5(2), 147-155.

Britzman, D. P. (1991). Practice makes Practice: A critical study of learning to teach. New York: State University of New York Press, Albany.

Britzman, D., Dippo, D., Searle, D. \& A. Pitt. (1997). Toward an Academic Framework for Thinking about Teacher Education. Teaching Education, 9(1), 15-26.

Brookfield, S. (1986). Understanding and facilitating adult learning. Jossey-Bass, San Francisco.

Dennan, P. (2008). Pedagogical Lurking: Student Engagement in Non-posting Discussion Behavior. Computers in Human Behavior, 24(4), 1624-1633.

Dippo, D, Duran M., Gilbert J. \& A. Pitt. (2008). Public Schooling, Public Knowledge, and the Education of Public School Teachers. In Cynthia Levine Rasky, Ed. Canadian Perspectives on the Sociology of Education, Oxford University Press: Toronto, Forthcoming.

Graham, C.R. (2004). Blended Learning Systems: Definition, Current Trends, and Future Directions. In Bonk, C. J. \& Graham, C. R., Eds. Handbook of blended learning: Global perspectives, local designs. San Francisco, CA: Pfeiffer Publishing, 3-21.

Gulati, S. (2008). Compulsory participation in online discussions: is this constructivism or normalization of learning? Innovations in Education and Teaching International, 45, 2, 183-192. Available: http://dx.doi.org/10.1080/14703290801950427

Harrington \& Quinn-Leering, (1996). Considering teaching consequences. Teaching and Teacher Education, 123, 591-607.

Hough, B. W., Smithey, M. W., \& Evertson, C. M. (2004). Using computer-mediated communication to create virtual communities of practice for intern teachers. Journal of Technology and Teacher Education, 14(3), 543-579.

Kelly, G. (1970). A brief introduction to personal construct theory. In D. Bannister (Ed.), Perspectives in personal construct theory. London: Academic Press, pp. 1-29.

Leach, L. Neutze, G. Zepke, N. (2001). Assessment and Empowerment: Some Critical Questions. Assessment and Evaluation in Higher Education, 26(4) pp. 293-306.

Mason R. (1998). Models of online courses. ALN Magazine, 2(2). Available: http://aln.org/alnweb/magazine/vol2 issue2/Masonfinal.html

Nonnecke, B., \& Preece, J. (2000). From Usenet to CoWebs VI. Available: 
http://www.cis.uoguelph.ca/ nonnecke/ research/silentparticipants.pdf

Semali, L.M. \& Watts Pailliotet, A. (1999). Intermediality: The Teachers' Handbook of Critical Media Literacy. Boulder, CO: Westview Press.

Tedves, A. (2010). LLED 452 Discussion posting comment, February 1.

Wells, G. (2002). Inquiry as an Orientation for Learning, Teaching and Teacher Education. In Wells, G. \& Claxton, G. (Eds.), Learning for life in the 21st century: sociocultural perspectives on the future of education. Oxford, UK; Malden, MA: Blackwell Publishers.

Zhao, Y. Englert, C.S. Chen, J. Jones, S.C. \& Ferdig, R.E. (2000). The development of a Web-based literacy learning environment: A dialogue between innovation and established practices. Journal of Research on Computing in Education, 32(4), 435-454.

\section{Author Biographies}

Karen Armstrong is a Course Director in the Faculty of Education at York University. She also writes and teaches online for University of British Columbia. Her doctoral dissertation was a paradigmatic analysis of $20^{\text {th }}$ century research on response to literature. Her current interests are online learning, multi-literacies, paradigm shifts and reading comprehension. karmstrong@edu.yorku.ca

Margaret Manson teaches in the Faculty of Education at York University. Her current research interests include inquiries into community-based practices of teaching and learning, and interdisciplinary studies of evolving arts practices in diasporic communities. mmanson@edu.yorku.ca

We would like to thank Lyndsay Moffatt and our anonymous reviewers for their helpful suggestions on an earlier version of this paper. 